\title{
OVIPOSITION PREFERENCE OF TWO SPECIES OF PSYLLID (CARDIASPINA ALBITEXTURA AND CARDIASPINA RETATOR) ON EUCALYPTUS CAMALDULENSIS LEAVES
}

\begin{abstract}
Nismah $^{1}$
ABSTRACT

Oviposition preference of two species of psyllid (Cardiaspina albitextura and Cardiaspina retator) on Eucalyptus camaldulensis leaves. Study on oviposition preference of two species of psyllid (Cardiaspina albitextura and Cardiaspina retator) on Eucalyptus camaldulensis was conducted in open area around Bundoora Campus, La Trobe Univesity, Australia. The purpose of this study was to examine the oviposision preference of two difference species of psyllid. Seven $E$. camaldulensis trees occupied by both $C$. albitextura and $C$. rotator were chosen. Leaves of $E$. camaldulesis were sampled in two periods of oviposition. Four E. camaldulensis trees labelled with t1, t2, t3 and t4 were sampled in period of oviposition I and seven trees in period of oviposition II ( 4 trees were same as trees in period I ( t1, t2, t3, t4 and 3 other trees t5, t6 and t7 ). Thirty randomly selected leaves, occupied by the eggs of both C. albitextura and C. rotator, were taken from each tree. The samples of leaves were brought to laboratory to examine the eggs on each side (adaxial and abaxial) of leaves. The eggs were counted under $10 \mathrm{x}$ magnifications and recorded. Correlation was used in the data analysis and significance of r-value was tested by $t$ test. The result indicated that both species of pest (C. albitextura and C. rotator) chose the same side of leave for oviposition. Both $C$. albitextur and C. retator prefer the abaxial surface of leaves to oviposit on most trees sampled in the field. The numbers of eggs oviposited by C. albitextur had a positive correlation with the number of eggs oviposited by C. retator. The number of eggs laid by both species depended on period of ovipositon, tree, and side where the eggs were laid.
\end{abstract}

Key words : Cardiaspina albitextura, Cardiaspina rotator, Eucalyptus camaldulensis, oviposition preferences, adaxial, abaxial

\section{INTRODUCTION}

Cardiaspina Crawford (Hemiptera: Psyllidae) is one of the most important genera of the Australian Psyllidae, owing to the spectacular damage it can cause to Eucalyptus spp. Periodically, over large areas of southern Australia, there have been devastating attacks by Cardiaspina spp. on eucalyptus (Morgan \& Bungey,1981). All known species of Cardiaspina cause death of the leaf tissues around the nymphal feeding sites. Outbreaks may often cause severe defoliation on heavily infested trees (Woodward et al., 1991).

The oviposition preference hypothesis (Thompson, 1988) states that if the quality of the environment in which eggs are laid influences offspring fitness, natural selection should have favoured females that oviposit in a site where offspring survival to final size is greatest. Yet field tests of this hypothesis have produced equivocal results (McClure et al., 1998). Many insects do prefer to oviposit on a host where offspring fitness is higher (Pasquier-Barre et al., 2000), some do so only under certain conditions (Quiring \& Butterworth, 1994), and others do not (Larsson \& Ekbom, 1995).
According to Gegechkori (1968), psyllids generally show narrow host specificity; species are limited to a single host plant species within a host genus. Mattson et al. (1987) state that insects with a narrow host range should be especially sensitive to intraspecific variation in plant characteristics. For example, almost all female Cardiaspina albitextura laid their eggs on fully expanded mature leaves while Glycaspis brimblecombei females usually lay their eggs on soft young leaves that are still expanding (White, 1971). The choice of a site may correlate with the quality of the individual leaf (Inbar et al., 1995)

This paper reports the results of a field study on the oviposition sites of two species of psyllid (C. albitextura and C. rotator) on E. camaldulensis leaves. An understanding of the oviposition sites of both psyllids is important to our knowledge of insect ecology. Detailed knowledge of the ecology of a pest is necessary to achieve successful control.

\section{MATERIALS AND METHODS}

This study sites were situated in the open parklands around La Trobe University Bundoora Campus Victoria Australia. Seven E. camaldulensis

\footnotetext{
${ }^{1}$ Lecturer at Department of Biology, Faculty of Mathematics and Natural Sciences, University of Lampung,

Jl. Prof. Soemantri Brodjonegoro No.1 Bandar Lampung 35145
} 
trees occupied by both $C$. albitextura and C. rotator were chosen. Leaves of $E$. camaldulesis were sampled in two periods of oviposition. Four E. camaldulensis trees labelled with $\mathrm{t} 1, \mathrm{t} 2, \mathrm{t} 3$ and $\mathrm{t} 4$ were sampled in period of oviposition I and seven trees in period of oviposition II (4 trees are same as trees in period I (t1, t2, t3, t4 and 3 other trees $t 5, t 6$ and $t 7$ ). Thirty randomly selected leaves, occupied by the eggs of both $C$. albitextura and C. rotator, were taken from each tree. The samples of leaves were brought to laboratory to examine the eggs on each side (adaxial and abaxial) of leaves. The eggs were counted under10 x magnifications and recorded. SPSS version 9.0 was the statistical program used in the data analysis. To stabilise the variances, data were transformed to $\log (\mathrm{x}+0.5)$, particularly for sets of data containing zeroes (Yamamura, 1999). Correlation was used in the data analysis and significance of r-value was tested by t test (Snedecor \& Cochran, 1980).

\section{RESULTS AND DISCUSSIONS}

The log number of eggs of $C$. albitextura had a positive correlation with the log number of eggs of C. retator $(P<0.001)$ (Figure1). The position where eggs were laid affected number of eggs laid by psyllids. Figure 2 below shows that both

$C$. albitextura $(\mathrm{Ca})$ and $C$. retator $(\mathrm{Cr})$ chose the abaxial surface of leaves to oviposit on most trees sampled in the field.

C. albitextura and C. retator tended to oviposit on the abaxial side of leaves. The number of eggs laid by both species depended on period of oviposition, tree and side where the eggs were laid. The differences might be caused by differences in time when the quantity of suitable food available on tree varied. The leaves of host plant may be "juvenile", "intermediate", or "mature" depending on tree age and condition (Jacobs, 1955).

Differences in conditions such as age, position, and quantity of leaves, affect the attractiveness of foliage for oviposition by $C$. albitextura on E. blakelyi. Heavy feeding either by nymphal or adult psyllids greatly reduces the attractiveness of leaves as oviposition sites. Relatively few eggs were laid on leaves damaged severely by nymphs and females invariably concentrated their eggs on only that part of the foliage, which escaped severe damage (Clark, 1963).
C. albitextura and $C$. retator chose the same abaxial side of the leaf for oviposition, due to their being closely related species. Consequently, they have some similarities in their general biology (Clark, 1962; White, 1971). For the surfaces on which the eggs are laid, there was a significant regression of log number of eggs laid by $C$. albitextura on those laid by C. retator, described by the equation $\mathrm{y}=0.44 \mathrm{x}+0.21$ (significant at $\alpha=0.001$ ) (Figure 1 ).

The selection for oviposition on the abaxial surface of the leaf may be related to the ability of the psyllids to adhere to such surface. Since the structure of adaxial surface of Eucalyptus leaves is more glaucous ('waxy') than the abaxial surface (Wirthensohn \& Sedgley, 1996), the psyllids' adhesion to this surface is reduced (Brennan \& Weinbaun, 2001a, b). Brennan and Weinbaun (2001a) found that the $G$. brimblecombei were able to climb the 'waxy' juvenile leaves of E. globulus only by clinging to protruding veins of abaxial leaf surfaces. Results of this study are also supported by the hypothesis of Eigenbrode and Espelie (1995) that states that the ovipositional preferences for glossy plants relate in part to the ability of insects to adhere to such plants. Plant epicuticular waxes affect insects both physically and chemically (Eigenbrode, 1996). Waxes can alter the slipperiness of a plant surface, which affects the adhesion of herbivores (Stork, 1980; Edward, 1982), predators (Eigenbrode et al., 1996, 1999), and ants (Federle et al., 1997).

Claridge \& Wilson (1978) stated that the oviposition patterns of most leafhoppers are very distinctive; they often prefer specific sites within a plant. Previous studies on oviposition patterns or preferences in leafhoppers have shown that most species have a very specific pattern and preference, and oviposition is more discriminating than nymphal feeding (Claridge \& Reynold, 1972; Claridge et al., 1977). Claridge \& Wilson (1978) concluded not only that many tree-associated leafhoppers are specific in their choice of host plant, but also that they usually have very characteristic modes of placement and insertion of eggs into the host tissues.

C. albitextura and C. retator were more inclined to lay their eggs on the leaves that were already occupied by eggs. These results support those of Clark (1963). In that study, which examined the effect of the presence of eggs on subsequent oviposition of C. albitextura on E. blakelyi 


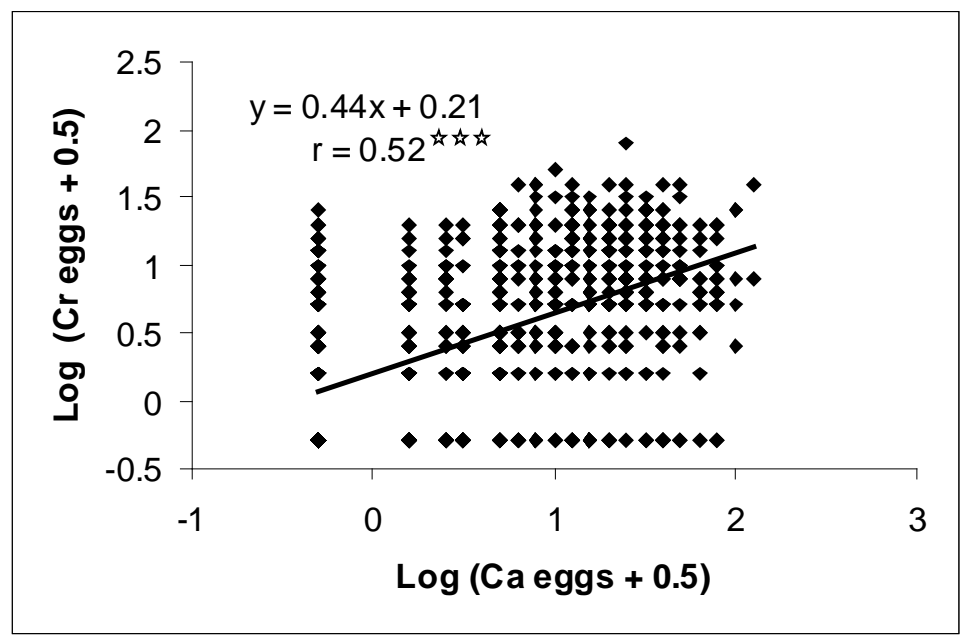

Figure 1. The correlation between log (number of eggs +0.5$)$ of C. albitextura (Ca) and log (number of eggs + $0.5)$ of $C$. retator $(\mathrm{Cr})$ on leaves of $E$. camaldulensis. (*** significant at $\alpha=0.001$ ).

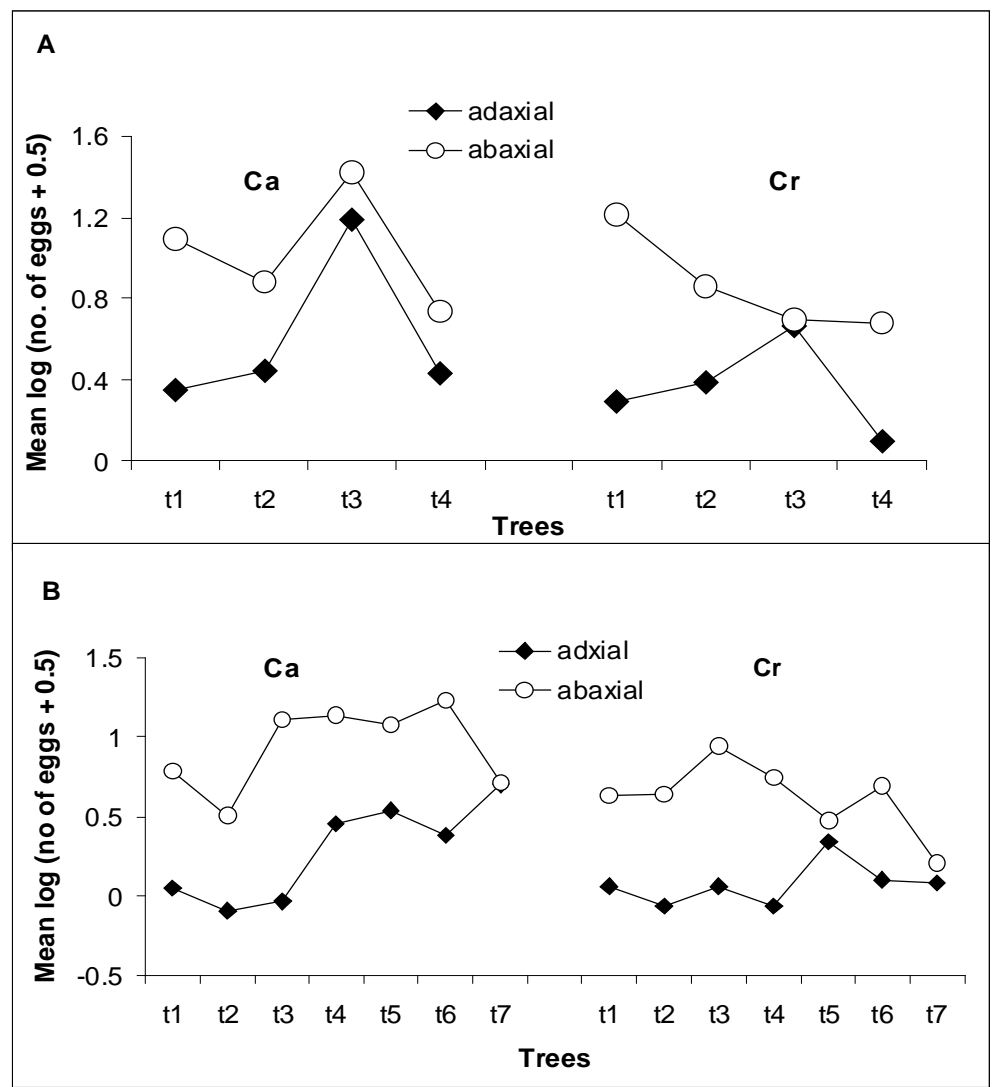

Figure 2 The comparison between the numbers of eggs laid by C. albitextura (Ca) and C. retator (Cr) on each surface of E. camaldulensis leaf (A = Period I and $\mathbf{B}=$ Period II). 
under natural conditions, he found that during the interval allowed for further oviposition; almost 25 times as many eggs were laid on surfaces with the original eggs present as on surfaces with the original eggs removed. Over $50 \%$ of the latter received no eggs, and there was no association between numbers added and initial numbers. For the surfaces on which the original eggs remained, there was a highly significant correlation of numbers added with numbers present initially. It is likely that the presence of eggs on a leaf not only increases its attractiveness as an oviposition site, in the proportion to the number already there, but also similarly limits feeding by adults, thus conserving food for the psyllid progeny (Clark \& Dallwitz, 1975).

Previous studies on the use of occupied sites for oviposition by tephritid fruit flies (Rhagoletis spp.) and Bactrocera spp. show resulting costs and benefits of use of occupied sites. The possible costs are 1) increased larval competition (Papaj and Prokopy, 1989), 2) increased adult competition (Papaj, 1994) and 3) increased parasitism of juvenile stages (Papaj, 1994). The possible benefits are 1) opportunity for ovicide of previously laid eggs (Visser et al., 1992), 2) improved larval performance (Messina, 1989), 3) reduced time expenditures by the females (Papaj, 1994) and 4) reduced ovipositor wear (Papaj, 1994).

\section{CONCLUSION}

C. albitextura and $C$. retator chose the same side of the leaf for oviposition, i.e. both psyllids preferred to oviposit on abaxial (below surface) of E. camaldulensis leaves. There has been positive correlation between numbers of eggs laid by C. albitextura with those laid by $C$. rotator. In the context of competition, it is assumed that oviposition site selection by females could increase the level of interspecific competition between their progeny, since any competition between the two species should be based on their simultaneous requirement for some resources, e.g., feeding sites and oviposition sites.

\section{ACKNOWLEDGMENTS}

This paper is a part of my $\mathrm{PhD}$ project. I would like to thank my supervisor Dr. S.A.Ward at Department of Zoology La Trobe University, Australia for his guidance and supervision throughout this project. Directors and staff of DUE project Unila for the grant and moral supports during my study in Australia.

\section{REFERENCES}

Brennan, E. B. \& S. A. Weinbaum. 2001a. Effect of epicuticular wax on adhesion of psyllids to glaucous juvenile and glossy adult leaves of Eucalyptus globulus Labillardiere. Aust. J. Ent. 40: 270-277.

--------. 2001b. Performance of adult psyllyds in nochoice experiments on juvenile and adult leaves of Eucalyptus globulus. Entomol. Exp. Appl. 100: 179-185.

Clark, L.R. 1962. The general biology of Cardiaspina albitextura (Psyllidae) and its abundance in relation to weather and parasitism. Aust. J. Zool. 10: 537-586.

1963. Factors affecting the attractiveness of foliage for oviposition by Cardiaspina albitextura (Psyllidae). Aust. J. Zool. 11: 2033.

Clark, L.R. \& M.J. Dallwitz. 1975. The life system of Cardiaspina albitextura (Psyllidae), 195074. Aust. J. Zool. 23: 523-561.

Claridge, M. F. \& W. J. Reynolds. 1972. Host plant specivicity, oviposition behavior and egg parasitism in some woodland leafhoppers of the genus Oncopsis (Hemiptera Homopreta: Cicadellidae) Trans. R. ent. Soc. Lond. 124: 149-166.

Claridge, M. F., W. J. Reynolds, \& M. R. Wilson. 1977. Oviposition behavior and food plant discrimination in leafhoppers of genus Oncopsis. Ecol. Ent. 2: 149-166.

Claridge, M. F. \& M. R. Wilson. 1978. Oviposition behavior as an ecological factor in woodland canopy leafhoppers. Entomol. Exp. Appl. 24: 101-109.

Edwards, P. B.1982. Do waxes on juvenile Eucalyptus leaves provide protection from grazing insects? Aust. J. Ecol. 7: 347-352. 
Eigenbrode, S. D. 1996. Plant surface waxes and insect behavior. in Plant cuticle. Edited by G. Kerstein. pp. 201-221. BIOS Scientific Publishers.

Eigenbrode, S. D. \& K. E. Espelie. 1995. Effects of plant epicuticular lipids on insect herbivorous. Ann. Rev. Entomol. 40: 171-194.

Eigenbrode, S. D., T. Castagnola. M. B. Roux, \& L. Steljes. 1996. Mobility of three generalist predators is greater on cabbage with glossy leaf wax than on cabbage with a wax bloom. Ent. Exp. Appl. 81: 335-343.

Eigenbrode, S. D., N. N. Kabalo, \& K. A. Stoner. 1999. Predation, behavior, and attachment by Chrysoperla plorabunda larvae on Brassica oleracea with different surface waxbloom. Ent. Exp. Appl. 90: 225-235.

Federle, W., U. Maschwitz. B. Fiala., M. Riederer, \& B. Holldobler. 1997. Slippery ant-plants and skillful climbers: Selection and protection of specific ant partners by epicuticular wax blooms in Macaranga (Euphobiaceae). Oecologia 112: 217-224.

Gegechkori, A. M. 1968. Materials for the study of diet of the Psyllidae (Homoptera: Psylloidea) narrowly specialized phytophagous. Soobshch. Nauk gruz. SSR 52: 509-514.

Inbar, M., A. Eshel, \& D. Wool. 1995. Interspecific competition among phloem-feeding insects mediated by induced host plant sinks. Ecology 79: 1506-1515

Jacobs, M. R. 1955. Growth habits of the eucalypts. Forestry And Timber Bureau. Department of the Interior. A.J. Arthur ed., Commonwealth Government Printer, Canberra. Printed in Australia.

Larsson, S. \& B. Ekbom. 1995. Oviposition mistakes in herbivorous insects: confusion or a step towards a new host plant? Oikos. 72: 155-160.

Mattson, W. J., R. K. Laurence. R.A. Haack., D. A. Herms, \& P. J. Charles. 1987. Defensive strategies of woody plants against different insect-feeding guilds in relation to plant ecological strategies and intimacy of associations with insects. in Mechanisms of Woody Plant Defenses against insects. Edited by W. J. Mattson, J. Levieux and C. BernardDagan). Springer. New York.

McClure, M., D. T. Quiring, \& J. J. Turgeon. 1998. Proximate and ultimate factors influencing oviposition site selection by endoparasites on conifer seed cones: two sympatric dipteran species on larch. Ent. Exp. Appl 87: 1-13.

Messina, F. J. 1989. Host-plant variables influencing spatial distribution of a frugivorous fly Rhagoletis indifferens. Entomol. Exp. Appl. 50: 287-294.

Morgan, F.D, \& R.S. Bungey. 1981.Dinamics of poplation outbreaks of psyllidae (Lerp insects) on eucalypts. In Eucalypt dieback in forests and woodlands. Edited by K.M. Old. G.A. Kile and C.P. Ohmart. CSIRO, Australia.

Papaj. D.R. 1994. Use and avoidance of occupied hosts as a dynamic process in tephrited flies in Insect-Plant interactions vol. V. Edited by Bernays.E.A. CRC Press Inc.

Papaj. D.R.\& R.J. Prokopy, 1989. Ecology and evolutionary aspects of learning in phytophagous insects. Annu.Rev. Entomol. 34: 315-350.

Pasquier-Barre, F., C. Geri. F. Goussard., M. A. Auger-Rozenberg, \& S. Grenier. 2000. Oviposition preference and larval survival of Diprion pini on scots pine clones in relation to foliage characteristics. Agri. Forest Entomol. 2: 185-192.

Quiring, D. T., \& E. R. Butterworth. 1994. Genotype and environment interact to influence acceptability and suitability of white spruce for a specialist herbivore, Zeiraphera canadensis. Ecol.Ent. 19: 230- 238.

Snedecor, G. W. \& W. G. Cochran. 1980. Statistical Methods. Seventh ed. The Ioa State University Press. 
Stork, N. E. 1980. Role of waxboom in preventing attachment to brassicas by the mustard beetle. Phaedon cochleariae. Entomol. Exp. Appl. 28: 100-107.

Thompson, J. N.1988. Evolutionary ecology of the relationship between oviposision preference and performance of offspring in phytopagous insects. Entomol. Exp. Appl. 47: 3-14.

Visser, M. E., J. J. M. van Alphen, \& L. Hemerik. 1992. Adaptive superparasitism and patch time allocation in solitary parasitoids: an ESS model. J. Anim. Ecol. 61: 93-101.

White, T. C. R. 1971. Lerp insects (Homoptera, Psyllidae) on red gum (E. camaldulensis) in South Australia. S. Aust. Nat. 46: 20-23.
Wirthensohn, M. G. \& M. Sedgley. 1996. Epicuticular wax structure and regeneration on developing juvenile Eucalyptus leaves. Aust. J. Bot. 44: 691-704.

Woodward, T. E., J. W. Evans. \& V.E. Eastop. 1991. Hemiptera (bugs, leafhoppers,etc). In The Insects of Australia: A textbook for students and research workers. Sponsored by the division of entomology commonwealth scientific and industrial research organisation Canberra. Melbourne Univ. Press.

Yamamura, K. 1999. Transformation using $(\mathrm{X}+0.5)$ to stabilize the variance of populations. Res. Popul. Ecol. 41: 229-234. 